\title{
R-PEP-27, a Potent Renin Inhibitor, Decreases Plasma Angiotensin II and Blood Pressure in Normal Volunteers
}

\author{
Randall M. Zusman, Kwan Y. Hui, Jürg Nussberger, Donna M. Christensen, Joy Higgins, \\ William D. Carlson, David Schoenfeld, and Edgar Haber
}

The hemodynamic and humoral effects of the specific human renin inhibitor R-PEP-27 were studied in six normal human subjects on low and high sodium intake diets. An intravenous infusion of R-PEP-27 $(0.5$ to $16 \mu \mathrm{g} / \mathrm{min} / \mathrm{kg}$ body $\mathrm{wt})$ reduced blood pressure in a dose-dependent fashion; the mean arterial blood pressure at the end of the infusion fell from $128 \pm 4 / 83 \pm 4$ to $119 \pm 3 / 71 \pm 3 \mathrm{~mm}$ $\mathrm{Hg}$ (mean $\pm \mathrm{SEM})(P<.01)$ during the low sodium intake diet. R-PEP-27 had no effect on blood pressure during the high sodium intake diet.
R-PEP-27 significantly reduced plasma angiotensin II and aldosterone concentrations. The temporal response to R-PEP-27 suggests that it is a shortlived although highly potent competitive inhibitor of renin; this peptide is a valuable and specific physiologic probe of the renin-angiotensin system. Am J Hypertens 1994;7:295-301

KEY WORDS: R-PEP-27, renin-angiotensin-aldosterone system, renin inhibitor.

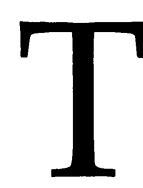
The renin-angiotensin-aldosterone system was first described as a regulator of systemic vascular resistance, intravascular volume, and blood pressure and as a circulating hormonal system mediated by the vasoconstricting octapeptide angiotensin II and the adrenal steroid aldo-

\footnotetext{
Received March 15, 1993. Accepted November 29, 1993.

From the Division of Hypertension and Vascular Medicine, Cardiac Unit (RMZ, KYH, DMC, JH, WDC, EH), and the Biostatistics Center (DS), Medical Services, Massachusetts General Hospital, and Department of Medicine, Harvard Medical School, Boston Massachusetts; and the Hypertension Division, University Hospital (JN), Lausanne, Switzerland.

This study was supported in part by grants from the National Aeronautics and Space Administration (NAG 9-151), the Division of Research Resources, National Institutes of Health General Clinical Research Center (RR0166-12), and the Cardiovascular Research Foundation, Lausanne, Switzerland.

The current address for Dr. Hui is Eli Lilly and Company, Lilly Corporate Center, Indianapolis, IN 46285. Dr. Haber's current address is Harvard School of Public Health, Boston, Massachusetts.

Address correspondence and reprint requests to Dr. Randall M. Zusman, Division of Hypertension and Vascular Medicine, Massachusetts General Hospital, 15 Parkman Street, WACC 482, Boston, MA 02114
}

sterone. Because of the importance of the reninangiotensin system in sustaining the blood pressure of hypertensive humans and the pathophysiologic role of perturbations of this system in congestive heart failure, attention has been focused on the development of inhibitors of the renin-angiotensin cascade. ${ }^{1,2}$ The first inhibitor of this system was saralasin, an angiotensin II receptor antagonist. ${ }^{3}$ More recently, non-peptide angiotensin II receptor antagonists have been developed; these substances, primarily imidazole derivatives, are effective in antagonizing angiotensin II-mediated vasoconstriction. Unlike saralasin, however, they have no agonistic activity; in addition, they can be administered orally rather than parenterally. ${ }^{4,5}$

Inhibition of the formation of angiotensin II through the use of angiotensin-converting enzyme (ACE) inhibitors has become clinically important in the treatment of patients with hypertension, congestive heart failure, or both. However, the specificity of their antihypertensive effect with regard to the reninangiotensin system has been questioned because of 
the efficacy of captopril, in particular, under conditions of renin suppression. The physiologic and therapeutic benefits of converting enzyme inhibition thus might result not only from inhibition of the reninangiotensin cascade, but also from non-reninmediated mechanisms of vasodilation. ${ }^{6}$

An alternative to angiotensin II receptor blockade or converting enzyme inhibition is interruption of the proximate step in the renin-angiotensin-aldosterone cascade, the inhibition of renin itself. The conversion of angiotensinogen to angiotensin $\mathrm{I}$ is the ratelimiting step in the generation of the biologic effector angiotensin II. Since the original description of a competitive renin-inhibitory peptide, ${ }^{7}$ a number of compounds have been described that inhibit renin's interaction with its sole substrate, angiotensinogen. ${ }^{8}$ These agents have the potential advantage of inhibiting the generation of angiotensin I within the intravascular space; in addition, if they penetrate into extravascular sites of renin activity, they could decrease intracellular angiotensin II generation. Intracellularly, the physiologic importance of the angiotensinconverting enzyme as a promoter of the formation of angiotensin II from angiotensin I has been questioned. Thus, the effects of a renin inhibitor might exceed those of ACE inhibition. The use of a competitive renin inhibitor as a physiologic probe might allow isolation of the effects of renin inhibition from the potential non-renin-dependent mechanisms of action of the converting enzyme inhibitors or angiotensin II receptor antagonists.

The renin inhibitory peptide R-PEP-27 (Pro-HisPro-Phe-His-Statine-Ile-Phe-NH2) is a potent substrate analog; its $\mathrm{IC}_{50}$ in vitro against human plasma renin at $\mathrm{pH} 7.4$ is $9.5 \mathrm{nmol} / \mathrm{L}$ when renin activity is measured by the antibody-trapping technique ${ }^{9}$ as adapted from Poulsen and Jorgensen, ${ }^{10}$ which indicates greater potency than that of other clinically tested renin inhibitors such as CGP 38560A or enalkiren (A-64662) and equivalent potency to the orally active renin inhibitor RO 42-5892. The infusion of this renin inhibitory peptide into sodium-depleted Macaca fascicularis monkeys produces a dosedependent reduction in blood pressure and plasma renin activity in association with a fall in plasma angiotensin II concentrations. ${ }^{11}$ The purpose of the present investigation was to determine the blood pressure, heart rate, and humoral effects of a graded infusion of the renin inhibitory peptide R-PEP-27 in human subjects during both dietary sodium restriction and sodium repletion.

\section{METHODS}

Six subjects (five men, one woman, age range 31 to 61 years) were studied. Each subject gave written informed consent before participation. The clinical pro- tocol was approved by the Subcommittee on Human Studies of the Committee on Research of the Massachusetts General Hospital.

Each subject was admitted to the General Clinical Research Center of the Massachusetts General Hospital and was given a metabolic diet containing either $200 \mathrm{mEq}$ or less than $10 \mathrm{mEq}$ of sodium; the diet contained $100 \mathrm{mEq}$ of potassium. All subjects had unlimited access to distilled water. On the sixth day of each diet, each subject received R-PEP-27. Each subject ingested the high and the low salt intake diet; the order of the diets was randomized among the six subjects. Urine was collected daily for the measurement of 24-h sodium, potassium, and creatinine excretion.

R-PEP-27 Infusion Protocol R-PEP-27 was synthesized and purified as previously described. ${ }^{11,12}$ The renin-inhibitory peptide, dissolved in a solution of $5 \%$ dextrose and water (final concentration, approximately $0.5 \mathrm{mg} / \mathrm{mL}$ ), was infused using a variable-rate Harvard infusion pump at $0.5,1,2,4,8$, and $16 \mu \mathrm{g} /$ $\mathrm{min} / \mathrm{kg}$ body wt. Each dose was infused consecutively for $10 \mathrm{~min}$, for a total of $60 \mathrm{~min}$. Blood pressure was measured by sphygmomanometer every $2 \mathrm{~min}$, beginning $30 \mathrm{~min}$ before the onset of the infusion until 60 min after completion of the infusion in the supine position. For the subsequent hour, blood pressure was determined every $15 \mathrm{~min}$ for an additional $60 \mathrm{~min}$ in both the supine and upright positions.

During the 9th minute of each 10-min interval, the subjects were placed in the upright position at an angle of $70^{\circ}$ using a mechanized tilt table. Blood pressure was determined in the upright position during the 10th minute before initiation of the next infusion period.

Blood samples for the measurement of angiotensin II and aldosterone concentrations were obtained every $10 \mathrm{~min}$ (immediately before the patient assumed the upright position) beginning $20 \mathrm{~min}$ before the beginning of the infusion until $1 \mathrm{~h}$ after completion of the infusion. Blood samples were obtained every 30 min during the final hour. A total of $510 \mathrm{~mL}$ of blood was removed during the two dietary experimental periods. The blood was collected into prechilled tubes, centrifuged in a refrigerated centrifuge, and immediately frozen for storage before assay.

Blood volumes removed for biochemical determinations were replaced by intravenous injection of an equal volume of normal saline solution. Continuous electrocardiographic monitoring was maintained throughout administration of the renin-inhibitory peptide and converting enzyme inhibitor. Aldosterone concentration (Aldosterone TKAL Radioimmunoassay Kit, Diagnostic Products, Los Angeles, CA) ${ }^{13,14}$ and angiotensin II concentrations ${ }^{15}$ were determined as previously described. 
Briefly, angiotensins were extracted from plasma by reversible adsorption to phenylsilylsilica, separated by reversed-phase HPLC, and eight fractions of $105 \mu \mathrm{L}$ mobile phase potentially containing angiotensin-(1-8)octapeptide were directly collected into $1-\mathrm{mL}$ albumin buffer for radioimmunoassay. Using these procedures, overall recovery of angiotensin II added to plasma is consistently above $85 \%$. If none of the eight HPLC fractions contained measurable angiotensin II, one fraction was considered to contain the peptide at the detection limit of $0.16 \mathrm{fmol}$; thus the minimal angiotensin II concentration that could be measured in $2 \mathrm{~mL}$ of plasma was $0.1 \mathrm{fmol} / \mathrm{mL}$.

Statistical Analysis Baseline values were determined by averaging blood pressure measurements or laboratory results obtained during the 30 -min period preceding administration of the renin inhibitor. Measurements at the end of each renin-inhibitor infusion dose and during subsequent observation were determined by averaging values over the final $4 \mathrm{~min}$ of each 10-min interval.

All data are presented as the mean \pm standard error of the mean. An analysis of variance (ANOVA) followed by $t$ tests was used to test whether the difference between baseline values and values obtained during infusion of the peptide were significant.

\section{RESULTS}

Metabolic Homeostasis Each subject achieved metabolic balance on or before the fifth day of each sodium intake diet. Neither urinary sodium excretion (less than $5 \mathrm{mEq}$ and $183 \pm 8 \mathrm{mEq} / 24 \mathrm{~h}$ ), potassium excretion $(77 \pm 7$ and $84 \pm 5 \mathrm{mEq} / 24 \mathrm{~h})$, nor creatinine excretion (1448 \pm 127 and $1468 \pm 115 \mathrm{mg} / 24 \mathrm{~h})$ during low and high salt intake diets, respectively, were affected by treatment with the renin inhibitor R-PEP-27.

Blood Pressure The renin inhibitor induced a dosedependent and significant reduction in systolic, diastolic, and mean arterial pressure (calculated as the diastolic blood pressure plus one-third the pulse pressure) measured in the supine position during ingestion of the low-sodium diet; the reductions in systolic, diastolic, and mean blood pressure at the end of the peptide infusion were $8.8 \pm 2.2,11.5 \pm 1.1$, and $10.4 \pm 1.9 \mathrm{~mm} \mathrm{Hg}(P<.01$ for each value $)$, respectively (Figure 1, Table 1).

The blood pressure remained significantly suppressed for $20 \mathrm{~min}$ after termination of the infusion. The renin inhibitor did not affect blood pressure during ingestion of the high salt intake diet.

The effects of the renin inhibitor on blood pressure were qualitatively similar when blood pressure was measured in the upright position. In the upright position, the renin inhibitor produced a drop in mean

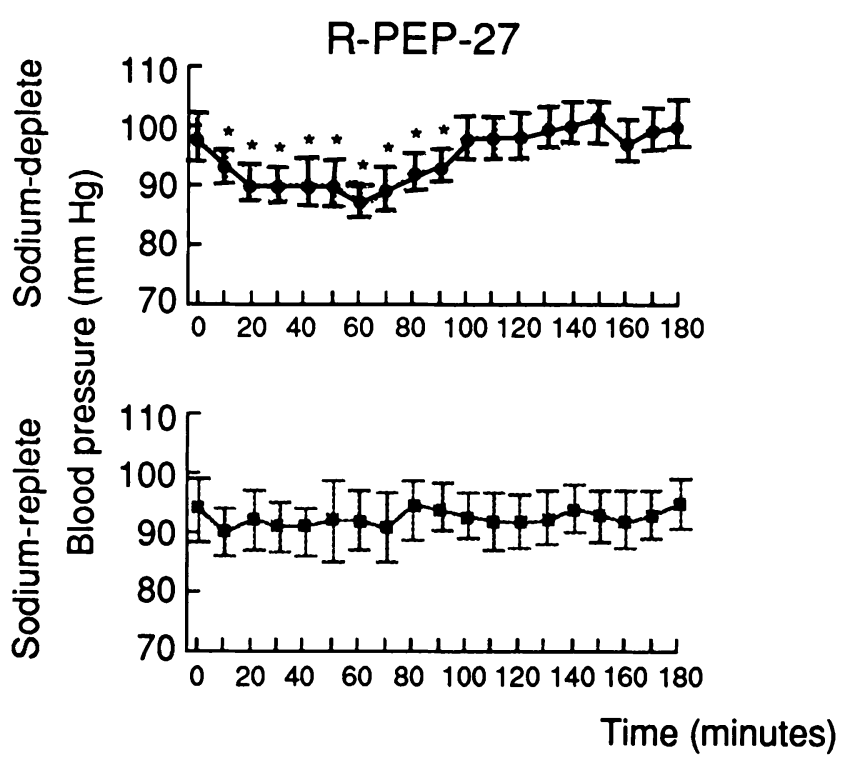

FIGURE 1. Effects of the renin inhibitor R-PEP-27 on mean arterial blood pressure measured in the supine position. The renin inhibitor R-PEP-27 was infused at $0.5,1,2,4,8$, and $16 \mu \mathrm{g} / \mathrm{kg} /$ min for 10 min each beginning at $t=0$, and ending at $t=60$ $\min .\left({ }^{*} \mathrm{P}<.05\right)$.

arterial blood pressure from $98 \pm 4$ to $86 \pm 4(P<.01)$ during the low salt intake diet; there was no blood pressure drop during the high salt intake diet.

Heart rate was unaffected by the renin-inhibitory peptide in the supine position (data not shown). Tilting into the upright position increased heart rate by $8.4 \pm 2.6$ beats $/ \mathrm{min}(P<.01)$ at the end of the renininhibitor infusion during the low sodium intake diet. There were no significant changes in heart rate in response to renin inhibition during the high sodium intake diet (data not shown).

Plasma Angiotensin II Concentration The renininhibitory peptide produced a dose-dependent reduction in plasma angiotensin II concentration during both diets (Figure 2). The numerical nadir in plasma angiotensin II concentration was reached during infusion of the $4-$ and $8-\mu \mathrm{g} / \mathrm{min} / \mathrm{kg}$ body wt doses of R-PEP-27 during the high and low salt intake diets, respectively. Angiotensin II concentrations measured after infusion of the renin inhibitor at 2, 4, 8, and 16 $\mu \mathrm{g} / \mathrm{kg} / \mathrm{min}$ did not differ significantly during the high salt intake diet. Plasma angiotensin II concentrations returned to pretreatment values in a time-dependent fashion after completion of the inhibitor infusion.

The fall in blood pressure during R-PEP-27 infusion correlated linearly with the fall in plasma angiotensin II; the equation for this relationship was: $y=0.82 x-$ 1.87 , with $y=$ change in mean arterial pressure $(\mathrm{mm}$ $\mathrm{Hg}$ ) and $\mathrm{x}=$ change in plasma angiotensin II concentration $(\mathrm{fmol} / \mathrm{mL})(\mathrm{r}=0.9, P<.01$ for both the slope and intercept of this regression equation). 
TABLE 1. EFFECTS OF RENIN INHIBITION ON BLOOD PRESSURE (SUPINE POSITION)

\begin{tabular}{|c|c|c|c|c|}
\hline \multirow[b]{3}{*}{ Time } & \multicolumn{4}{|c|}{ Blood Pressure (mm Hg) } \\
\hline & \multicolumn{2}{|c|}{ Sodium-Deplete Diet } & \multicolumn{2}{|c|}{ Sodium-Replete Diet } \\
\hline & Systolic & Diastolic & Systolic & Diastolic \\
\hline-30 & $126 \pm 5$ & $84 \pm 4$ & $129 \pm 8$ & $79 \pm 6$ \\
\hline-28 & $126 \pm 6$ & $85 \pm 4$ & $128 \pm 7$ & $79 \pm 5$ \\
\hline-26 & $134 \pm 4$ & $85 \pm 3$ & $128 \pm 8$ & $78 \pm 5$ \\
\hline-24 & $128 \pm 6$ & $84 \pm 4$ & $128 \pm 8$ & $80 \pm 5$ \\
\hline-22 & $126 \pm 7$ & $83 \pm 4$ & $129 \pm 8$ & $78 \pm 4$ \\
\hline-18 & $127 \pm 6$ & $84 \pm 4$ & $129 \pm 9$ & $78 \pm 6$ \\
\hline-16 & $130 \pm 6$ & $80 \pm 5$ & $127 \pm 8$ & $75 \pm 6$ \\
\hline-14 & $126 \pm 6$ & $81 \pm 5$ & $130 \pm 9$ & $73 \pm 7$ \\
\hline-12 & $127 \pm 5$ & $80 \pm 5$ & $128 \pm 8$ & $76 \pm 5$ \\
\hline-8 & $125 \pm 5$ & $81 \pm 5$ & $129 \pm 8$ & $75 \pm 4$ \\
\hline-6 & $130 \pm 5$ & $82 \pm 5$ & $132 \pm 7$ & $78 \pm 5$ \\
\hline-4 & $130 \pm 5$ & $82 \pm 5$ & $126 \pm 7$ & $74 \pm 6$ \\
\hline-2 & $128 \pm 5$ & $83 \pm 5$ & $126 \pm 8$ & $77 \pm 4$ \\
\hline 2 & $126 \pm 4$ & $80 \pm 4$ & $128 \pm 8$ & $75 \pm 5$ \\
\hline 4 & $128 \pm 3$ & $78 \pm 4$ & $125 \pm 7$ & $75 \pm 5$ \\
\hline 6 & $127 \pm 3$ & $79 \pm 3$ & $121 \pm 6$ & $75 \pm 4$ \\
\hline 8 & $122 \pm 3$ & $77 \pm 3$ & $122 \pm 6$ & $74 \pm 5$ \\
\hline 12 & $122 \pm 3$ & $79 \pm 3$ & $126 \pm 6$ & $73 \pm 4$ \\
\hline 14 & $123 \pm 2$ & $78 \pm 5$ & $126 \pm 7$ & $77 \pm 5$ \\
\hline 16 & $121 \pm 4$ & $77 \pm 3$ & $125 \pm 6$ & $75 \pm 4$ \\
\hline 18 & $120 \pm 2$ & $74 \pm 4$ & $126 \pm 6$ & $76 \pm 5$ \\
\hline 22 & $126 \pm 4$ & $75 \pm 5$ & $125 \pm 4$ & $76 \pm 4$ \\
\hline 24 & $122 \pm 3$ & $75 \pm 5$ & $126 \pm 5$ & $74 \pm 4$ \\
\hline 26 & $120 \pm 2$ & $76 \pm 3$ & $129 \pm 7$ & $75 \pm 4$ \\
\hline 28 & $122 \pm 2$ & $74 \pm 2$ & $124 \pm 7$ & $73 \pm 4$ \\
\hline 32 & $128 \pm 6$ & $75 \pm 5$ & $130 \pm 7$ & $73 \pm 6$ \\
\hline 34 & $125 \pm 4$ & $76 \pm 5$ & $122 \pm 5$ & $74 \pm 4$ \\
\hline 36 & $125 \pm 6$ & $76 \pm 3$ & $126 \pm 7$ & $73 \pm 4$ \\
\hline 38 & $118 \pm 4$ & $72 \pm 4$ & $124 \pm 5$ & $75 \pm 4$ \\
\hline 42 & $121 \pm 6$ & $75 \pm 5$ & $130 \pm 8$ & $74 \pm 4$ \\
\hline 44 & $122 \pm 4$ & $74 \pm 4$ & $127 \pm 8$ & $74 \pm 6$ \\
\hline 46 & $121 \pm 3$ & $74 \pm 4$ & $129 \pm 9$ & $72 \pm 6$ \\
\hline 48 & $122 \pm 3$ & $73 \pm 5$ & $129 \pm 11$ & $75 \pm 6$ \\
\hline 52 & $120 \pm 5$ & $72 \pm 4$ & $125 \pm 8$ & $74 \pm 4$ \\
\hline 54 & $123 \pm 4$ & $75 \pm 4$ & $128 \pm 9$ & $72 \pm 4$ \\
\hline 56 & $119 \pm 3$ & $70 \pm 4$ & $129 \pm 9$ & $74 \pm 4$ \\
\hline 58 & $121 \pm 2$ & $72 \pm 3$ & $128 \pm 10$ & $74 \pm 4$ \\
\hline 62 & $120 \pm 4$ & $74 \pm 5$ & $128 \pm 9$ & $74 \pm 5$ \\
\hline 64 & $118 \pm 4$ & $74 \pm 5$ & $126 \pm 9$ & $72 \pm 5$ \\
\hline 66 & $118 \pm 4$ & $75 \pm 4$ & $126 \pm 9$ & $74 \pm 6$ \\
\hline 68 & $120 \pm 3$ & $75 \pm 4$ & $124 \pm 9$ & $75 \pm 5$ \\
\hline 72 & $121 \pm 5$ & $70 \pm 5$ & $130 \pm 7$ & $76 \pm 4$ \\
\hline 74 & $123 \pm 4$ & $78 \pm 5$ & $131 \pm 9$ & $72 \pm 4$ \\
\hline 76 & $126 \pm 4$ & $77 \pm 5$ & $131 \pm 10$ & $77 \pm 6$ \\
\hline 78 & $125 \pm 2$ & $77 \pm 5$ & $131 \pm 8$ & $77 \pm 3$ \\
\hline 82 & $125 \pm 2$ & $79 \pm 3$ & $127 \pm 4$ & $78 \pm 4$ \\
\hline 84 & $122 \pm 3$ & $79 \pm 2$ & $129 \pm 7$ & $76 \pm 5$ \\
\hline 86 & $121 \pm 3$ & $77 \pm 4$ & $131 \pm 7$ & $75 \pm 3$ \\
\hline 88 & $125 \pm 3$ & $80 \pm 4$ & $129 \pm 7$ & $75 \pm 4$ \\
\hline 92 & $125 \pm 5$ & $82 \pm 4$ & $127 \pm 6$ & $78 \pm 4$ \\
\hline 94 & $130 \pm 3$ & $83 \pm 4$ & $127 \pm 6$ & $76 \pm 4$ \\
\hline 96 & $131 \pm 5$ & $85 \pm 4$ & $126 \pm 7$ & $76 \pm 4$ \\
\hline 98 & $128 \pm 6$ & $81 \pm 4$ & $125 \pm 7$ & $76 \pm 5$ \\
\hline 102 & $125 \pm 6$ & $82 \pm 4$ & $122 \pm 7$ & $75 \pm 5$ \\
\hline 104 & $129 \pm 4$ & $84 \pm 2$ & $129 \pm 6$ & $75 \pm 4$ \\
\hline 106 & $129 \pm 4$ & $83 \pm 3$ & $128 \pm 7$ & $75 \pm 5$ \\
\hline 108 & $129 \pm 4$ & $84 \pm 3$ & $125 \pm 7$ & $73 \pm 4$ \\
\hline 112 & $128 \pm 4$ & $83 \pm 3$ & $127 \pm 7$ & $74 \pm 5$ \\
\hline
\end{tabular}

TABLE 1. continued

\begin{tabular}{|c|c|c|c|c|}
\hline \multirow[b]{3}{*}{ Time } & \multicolumn{4}{|c|}{ Blood Pressure (mm Hg) } \\
\hline & \multicolumn{2}{|c|}{ Sodium-Deplete Diet } & \multicolumn{2}{|c|}{ Sodium-Replete Diet } \\
\hline & Systolic & Diastolic & Systolic & Diastolic \\
\hline 114 & $129 \pm 4$ & $82 \pm 4$ & $130 \pm 6$ & $73 \pm 4$ \\
\hline 116 & $126 \pm 6$ & $82 \pm 4$ & $128 \pm 7$ & $74 \pm 4$ \\
\hline 118 & $129 \pm 7$ & $83 \pm 4$ & $129 \pm 6$ & $75 \pm 4$ \\
\hline 125 & $129 \pm 5$ & $82 \pm 5$ & $129 \pm 7$ & $73 \pm 4$ \\
\hline 128 & $132 \pm 4$ & $83 \pm 4$ & $129 \pm 7$ & $74 \pm 4$ \\
\hline 135 & $131 \pm 4$ & $83 \pm 4$ & $129 \pm 6$ & $77 \pm 4$ \\
\hline 138 & $132 \pm 4$ & $84 \pm 3$ & $127 \pm 6$ & $77 \pm 4$ \\
\hline 145 & $133 \pm 3$ & $84 \pm 4$ & $127 \pm 5$ & $75 \pm 4$ \\
\hline 148 & $130 \pm 4$ & $87 \pm 3$ & $128 \pm 8$ & $77 \pm 3$ \\
\hline 155 & $130 \pm 4$ & $81 \pm 3$ & $128 \pm 7$ & $73 \pm 5$ \\
\hline 158 & $128 \pm 3$ & $80 \pm 5$ & $125 \pm 6$ & $77 \pm 5$ \\
\hline 165 & $132 \pm 5$ & $81 \pm 4$ & $130 \pm 8$ & $75 \pm 4$ \\
\hline 168 & $132 \pm 3$ & $85 \pm 3$ & $127 \pm 7$ & $76 \pm 3$ \\
\hline 175 & $131 \pm 2$ & $85 \pm 4$ & $130 \pm 6$ & $76 \pm 4$ \\
\hline 178 & $130 \pm 4$ & $86 \pm 5$ & $132 \pm 7$ & $79 \pm 3$ \\
\hline
\end{tabular}

Values recorded are the mean $\pm \operatorname{SEM}(n=6)$ of blood pressures recorded in the supine position. The value reported at time $=0$ in Figure 1 represents the average of 12 recordings for each subject obtained during the $30 \mathrm{~min}$ immediately before starting the infusion of $R-P E P-27$. The renin inhibitor was infused at rates of $0.5(t$ $=0$ to $10 \mathrm{~min}), 1(t=10$ to $20 \mathrm{~min}), 2(t=20$ to $30 \mathrm{~min}), 4(t=30$ to $40 \mathrm{~min})$, $8(t=40$ to $50 \mathrm{~min})$, and $16(t=50$ to $60 \mathrm{~min}) \mu \mathrm{g} / \mathrm{min} / \mathrm{kg}$.

Plasma Aldosterone Concentration Plasma aldosterone concentration was depressed in a dosedependent fashion by the renin inhibitor during both diets (Figure 3). During salt restriction, the nadir in plasma aldosterone concentration was reached at the end of the infusion period. Plasma aldosterone concentration increased in a time-dependent fashion after termination of the infusion. During the high salt diet, little change from a lower baseline plasma aldosterone concentration was observed.

Adverse Effects In one patient the infusion of R-PEP-27 was associated with the development of second-degree Wenkebach-type atrioventricular block. Atrioventricular block occurred in this patient during both study periods during the infusion of 16

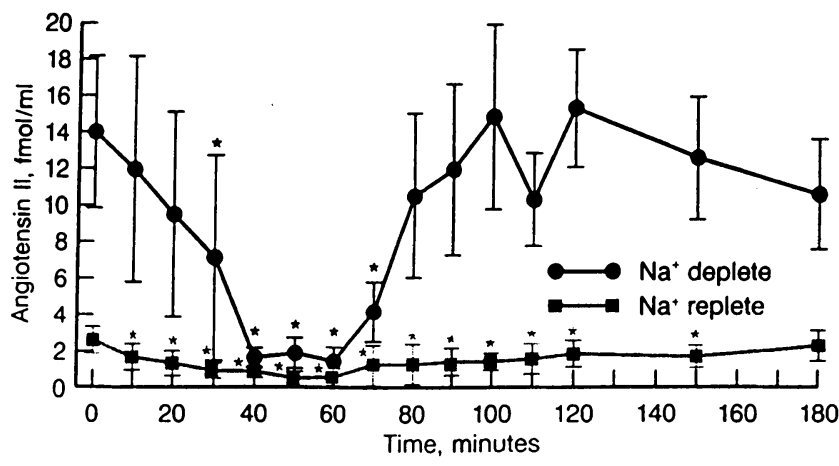

FIGURE 2. Effects of the renin inhibitor R-PEP-27 on plasma angiotensin II concentrations $(* \mathrm{P}<.05)$. 


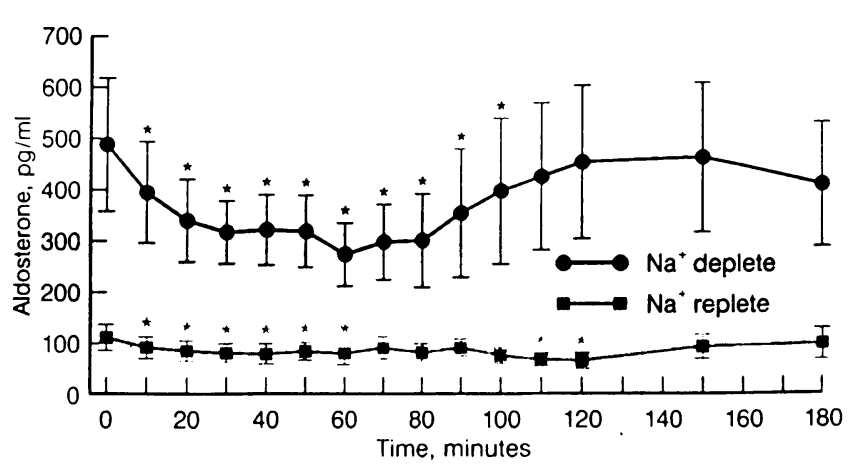

FIGURE 3. Effects of the renin inhibitor R-PEP-27 on plasma aldosterone concentrations $\left({ }^{*} \mathrm{P}<.05\right)$.

$\mu \mathrm{g} / \mathrm{min} / \mathrm{kg}$ body wt R-PEP-27. Normal atrioventricular conduction was restored within $10 \mathrm{~min}$ of discontinuing the infusion. None of the other five subjects exhibited any electrocardiographic abnormalities.

\section{DISCUSSION}

The reduction in blood pressure after administration of the renin inhibitor R-PEP-27 was limited to subjects on a sodium-restricted diet; subjects receiving the diet containing $200 \mathrm{mEq}$ of sodium daily had no hemodynamic response. Of particular note is the striking parallelism of the fall in blood pressure (Figure 1) and changes in plasma angiotensin II concentrations (Figure 2). The temporal pattern of blood pressure fall and subsequent recovery after renin inhibition is virtually identical to the changes seen in angiotensin II concentrations. On the low salt diet, plasma angiotensin II concentration and blood pressure were both lowest after infusion of the renin inhibitor for 60 $\mathrm{min}$; during the postinfusion period, angiotensin II levels were no longer suppressed $20 \mathrm{~min}$ after, and blood pressure was no longer suppressed $30 \mathrm{~min}$ after discontinuing the R-PEP-27 infusion. This relationship suggests that measurement of plasma angiotensin II concentrations is the most direct means of following the physiologic response to inhibition of the renin-angiotensin system.

Similar striking parallelism was observed by comparing the angiotensin II profiles (Figure 2) with the aldosterone profiles (Figure 3) of our volunteers. As with blood pressure, more marked decreases in plasma aldosterone concentrations were found during the low salt diet. Within an hour after stopping the renin-inhibitor infusion, aldosterone levels returned to baseline, as did angiotensin II concentrations and blood pressure. The increase in aldosterone levels after discontinuation of the infusion of the renin inhibitor and after a rapid increase in plasma angiotensin II concentrations demonstrates a specific post-drug effect.

The time-course of the renin inhibitory peptide's antihypertensive effect suggests that R-PEP-27 is a short-lived inhibitor of the renin-angiotensin system. Within $30 \mathrm{~min}$ after the renin inhibitor was discontinued, blood pressure, angiotensin II concentration, and plasma aldosterone concentration returned to baseline or nearly baseline values.

Our studies did not include a placebo observation period. Although the inclusion of such a period is often desirable, we believe our findings remain valid and are in no way diminished by the lack of a control group. The prolonged pretreatment observation period established a stable baseline for subsequent comparison and the return of blood pressure after termination of the infusion to the precisely identical blood pressure as in the preinfusion period points to the stability of the patients' blood pressures throughout our experiment and the statistical validity of the comparisons.

Varying responses have been observed in human subjects treated with renin-inhibitory peptides. Webb et $\mathrm{al}^{16}$ studied the hemodynamic response to the renin inhibitor H-142 (Pro-His-Pro-Phe-His-Len-Val-IleHis-Lys) in subjects on a low salt diet who had been pretreated $72 \mathrm{~h}$ before the study with oral furosemide. Renin inhibition significantly reduced blood pressure in a dose-dependent fashion, and the plasma angiotensin concentration and renin activity fell. After discontinuation of the infusion, there was a rebound in plasma renin activity and angiotensin II concentrations above baseline, although blood pressure did not exceed pretreatment values. Nussberger and colleagues ${ }^{17}$ reported that in normal subjects on an unrestricted diet who were pretreated with furosemide (40 mg orally), the administration of CGP$38560 \mathrm{~A}(\mathrm{~N}-(2(R)$-benzyl-3-tert-butyl-sulfonylproprionyl)His-Cha-Val- $n$-butylamide) did not affect blood pressure despite significant reductions in plasma renin activity and angiotensin II concentration. Similarly, Delabays and colleagues ${ }^{18}$ reported only a slight reduction in blood pressure in normal subjects treated with enalkiren ([N-(3-amino-3methyl-1-oxobutyl)-4-methoxy-L-phenylalanyl]- $N$ $[(1 S, 2 R, 3 S)-(1-c y c l o h e x y l-m e t h y l)-2,3-d i h y d r o x y-5-$ methylhexyl]-L-histidinamide) (Abbott 64662) despite significant reductions in plasma renin activity and plasma angiotensin II concentration. Total and active renin concentration in these subjects increased significantly during administration of the renin inhibitor, ${ }^{18}$ as in other studies of the effects of renin inhibition. ${ }^{19}$ Anderson et $\mathrm{al}^{20}$ have demonstrated that enalkiren significantly reduces the blood pressure, plasma renin activity, and plasma aldosterone concentration in hypertensive subjects, but does not change urinary prostacyclin excretion.

The collective experience to date with renin inhibitors shows that the response to renin inhibition de- 
pends on the dietary sodium intake, the species studied, and the chemical structure of the renin inhibitor used. Indeed, the mechanism of the hypotensive response to a renin inhibitor can differ depending on the volume of distribution of the substance, its ability to penetrate into extravascular sites of renin activity, and its half-life. Experimental studies have shown that the renin inhibitor $\mathrm{N}$-acetyl pepstatin suppresses vascular renin activity in isolated perfused rat mesenteric arteries, ${ }^{21}$ whereas CGP-29287 has no effect on tissue renin activity measured in the brain, heart, aorta, and kidney of the marmoset. ${ }^{22}$

Whether R-PEP-27 penetrates tissue sites of renin activity cannot be determined with certainty from this study. Indeed, in view of evidence that angiotensin I plays a role in cardiac contraction and relaxation, ${ }^{23-26}$ measurement of the systolic and diastolic properties of the myocardium of patients receiving ACE inhibitors and/or renin inhibitors might demonstrate a different pattern of cardiac response to interruption of the renin-angiotensin cascade proximal to or distal to the generation of angiotensin I.

No evidence currently shows that renin inhibitors offer a distinct hemodynamic advantage over angiotensin converting enzyme inhibitors in ambulatory hypertensive patients. Certainly, were a clinically effective orally active renin inhibitor available for human use, ${ }^{27-29}$ it might offer an advantage for patients who experience side effects from converting enzyme inhibition that are related to the non-reninmediated mechanism of action of these drugs; these side effects can include cough, angioedema, and skin rash. A specific, rapidly acting renin inhibitor could be of clinical utility for the treatment of patients with accelerated or malignant hypertension, or for those with acute congestive heart failure. Also, it could be valuable for the treatment of patients who are unable to take oral antihypertensive medications. Further studies with R-PEP-27 will be required to determine whether this peptide meets these requirements.

\section{REFERENCES}

1. Dzau VJ, Pratt RE: Renin-angiotensin system, in Fozzard HA, Haber E, Jennings CRB, et al (eds): The Heart and Cardiovascular System, (Ed. 2). New York, Raven Press, 1991, pp 1817-1849.

2. Hollenberg NK, Williams GH: Abnormal renal function, sodium volume homeostasis, and renin system behavior in normal-renin essential hypertension, in Laragh JH, Brenner BM (eds): Hypertension: Pathophysiology, Diagnosis, and Management. New York, Raven Press, 1990, pp 1349-1370.

3. Streeten DHP, Anderson GH: Angiotensin-receptor blocking drugs, in Doyle AE (ed): Handbook of Hypertension (Volume 5): Clinical Pharmacology of Antihypertensive Drugs. Amsterdam, Elsevier, 1984, pp 246-271.

4. Timmermans PBMWM, Carini DJ, Chiu AT, et al: The discovery and physiological effects of a new class of highly specific angiotensin II-receptor antagonists, in Laragh JH, Brenner BM (eds): Hypertension: Pathophysiology, Diagnosis and Management. New York, Raven Press, 1990, pp 2351-2360.

5. Christen Y, Waeber B, Nussberger J, et al: Oral administration of DuP 753, a specific angiotensin II receptor antagonist, to normal male volunteers. Circulation 1991;83:1333-1342.

6. Zusman RM: Renin- and non-renin-mediated antihypertensive actions of converting enzyme inhibitors. Kidney Int 1984;25:969-983.

7. Burton J, Cody RJ Jr, Herd JA, Haber E: Specific inhibition of renin by an angiotensinogen analog: Studies in sodium depletion and renin-dependent hypertension. Proc Natl Acad Sci USA 1980;77:5476-5479.

8. Haber E, Hui KY: Specific renin inhibitors: The concept and the prospects, in Laragh $\mathrm{JH}$, Brenner BM (eds): Hypertension: Pathophysiology, Diagnosis, and Management. New York, Raven Press, 1990, pp 23432350.

9. Nussberger J, Fasanella d'Amore T, Porchet M, et al: Repeated administration of the converting enzyme inhibitor cilazapril to normal volunteers. J Cardiovasc Pharmacol 1987;9:39-44.

10. Poulsen $\mathrm{K}$, Jorgensen J: An easy radioimmunological microassay of renin activity, concentration and substrate in human and animal plasma and tissues based on angiotensin I trapping by antibody. J Clin Endocrinol Metab 1974;39:816-825.

11. Hui KY, Knight DR, Nussberger J, et al: Effects of renin inhibition in the conscious primate Macaca fascicularis. Hypertension 1989;14:480-487.

12. Hui KY, Carlson WD, Bernatowicz MS, Haber E: Analysis of structure-activity relationships in renin substrate analogue inhibitory peptides. J Med Chem 1987;30:1287-1295.

13. Demers LM, Sampson E, Hayes AH Jr: Plasma and urinary aldosterone measurement in healthy subjects with a radioimmunoassay kit not requiring chromatography. Clin Biochem 1976;9:243-246.

14. Tan SY, Noth R, Mulrow PJ: Direct nonchromatographic radioimmunoassay of aldosterone: Validation of a commercially available kit and observations on age-related changes in concentrations in plasma. Clin Chem 1978;24:1531-1533.

15. Nussberger J, Brunner D, Waeber B, Brunner HR: True versus immunoreactive angiotensin II in human plasma. Hypertension 1985;7(suppl I):I-1-I-7.

16. Webb DJ, Manhem PJO, Ball SG, et al: A study of the renin inhibitor H142 in man. J Hypertens 1985;3:653 658.

17. Nussberger J, Delabays A, DeGasparo M, et al: Hemodynamic and biochemical consequences of renin inhibition by infusion of CGP $38560 \mathrm{~A}$ in normal volunteers. Hypertension 1989;13:948-953.

18. Delabays A, Nussberger J, Porchet $M$, et al: Hemodynamic and humoral effects of the new renin inhibitor enalkiren in normal humans. Hypertension 1989;13: 941-947.

19. Jeunemaitre $X$, Menard J, Nussberger J, et al: Plasma 
angiotensins, renin, and blood pressure during acute renin inhibition by CGP $38560 \mathrm{~A}$ in hypertensive patients. Am J Hypertens 1989;2:819-827.

20. Anderson PW, Do YS, Schambelan M, et al: The effects of renin inhibition in hypertensive man. Am J Cardiol (in press).

21. Saito H, Nakamura M, Ogihara T, et al: Renin inhibitor and converting enzyme inhibitors suppress vascular angiotensin II. Hypertension 1989;13:749-753.

22. Wood JM, Baum H-P, Carleton J, Dzau VJ: Inhibition of renin-like activity in marmoset tissues by the renin inhibitor CGP29287. J Hypertens 1987;5(suppl 2):S67S69.

23. Fouad-Tarazi FM, Bumpus FM: The renin-angiotensin system and treatment of heart failure, in Cardioprotection by Converting Enzyme Inhibition. Princeton, NJ, Excerpta Medica, 1988, pp 3-8.

24. Hirakata H, Fouad-Tarazi FM, Bumpus FM, et al: Angiotensins and the failing heart: Enhanced positive inotropic response to angiotensin I in cardiomyo- pathic hamster heart in the presence of captopril. Circ Res 1990;66:891-899.

25. Schunkert H, Dzau VJ, Tang SS, et al: Increased rat cardiac angiotensin converting enzyme activity and in RNA expression in pressure overload left ventricular hypertrophy: Effects on coronary resistance, contractility and relaxation. J Clin Invest 1990;86:1913-1920.

26. Lorell BH, Weinberg EO, Ngoy S, Apstein C: Angiotensin II directly impairs diastolic function in pressure overload hypertrophy. Circulation 1990;82:111112.

27. Pals DT, Thaisrivongs S, Lawson JA, et al: An orally active inhibitor of renin. Hypertension 1986;8:1105-1112.

28. Hiwada K, Kokubu T, Murakami E, et al: A highly potent and long-acting oral inhibitor of human renin. Hypertension 1988;11:708-712.

29. Camenzind E, Nussberger J, Juillerat L, et al: Effect of the renin response during renin inhibition: Oral RO42-5892 in normal man. J Cardiovasc Pharmacol 1991;18:299-307. 